OPEN ACCESS

Edited by:

Frederic Beca

University of Poitiers, France

Reviewed by:

Richard B. Moss,

Stanford University, United States

Raymond Pickles,

University of North Carolina at Chapel

Hill, United States

${ }^{*}$ Correspondence:

Anthony Kicic

anthony.kicic@telethonkids.org.au

†These authors share co-senior authorship

Specialty section:

This article was submitted to Pharmacology of Ion Channels and

Channelopathies,

a section of the journal

Frontiers in Pharmacology

Received: 31 July 2018 Accepted: 17 October 2018 Published: 07 November 2018

Citation:

Ling K-M, Garratt LW, Lassmann T, Stick SM, Kicic A, WAERP, AusREC

and Australian Respiratory Early Surveillance Team for Cystic Fibrosis (2018) Elucidating the Interaction of

CF Airway Epithelial Cells and Rhinovirus: Using the Host-Pathogen Relationship to Identify Future

Therapeutic Strategies.

Front. Pharmacol. 9:1270

doi: 10.3389/fphar.2018.01270

\section{Elucidating the Interaction of CF Airway Epithelial Cells and Rhinovirus: Using the Host-Pathogen Relationship to Identify Future Therapeutic Strategies}

\author{
Kak-Ming Ling 1,2, Luke W. Garratt ${ }^{2}$, Timo Lassmann², Stephen M. Stick ${ }^{1,2,3,47}$, \\ Anthony Kicic ${ }^{1,2,3,4,5 * t}$, WAERP ${ }^{1}$, AusREC ${ }^{1,6,7}$ \\ and Australian Respiratory Early Surveillance Team for Cystic Fibrosis ${ }^{1,3,8,9}$
}

${ }^{1}$ Paediatrics, Medical School, Faculty of Healthy and Medical Science, University of Western Australia, Nedlands, WA, Australia, ${ }^{2}$ Telethon Kids Institute, University of Western Australia, Nedlands, WA, Australia, ${ }^{3}$ Department of Respiratory Medicine, Princess Margaret Hospital for Children, Perth, WA, Australia, ${ }^{4}$ Centre for Cell Therapy and Regenerative

Medicine, School of Medicine and Pharmacology, University of Western Australia, Nedlands, WA, Australia, ${ }^{5}$ Occupation and Environment, School of Public Health, Curtin University, Bentley, WA, Australia, ${ }^{6}$ Robinson Research Institute, University of Adelaide, Adelaide, SA, Australia, ${ }^{7}$ Hunter Medical Research Institute: Priority Research Centre for Asthma and Respiratory Disease, New Lambton Heights, NSW, Australia, ${ }^{8}$ Murdoch Children's Research Institute, Melbourne, VIC, Australia,

${ }^{9}$ Department of Paediatrics, University of Melbourne, Melbourne, VIC, Australia

Chronic lung disease remains the primary cause of mortality in cystic fibrosis (CF). Growing evidence suggests respiratory viral infections are often more severe in CF compared to healthy peers and contributes to pulmonary exacerbations (PEx) and deterioration of lung function. Rhinovirus is the most prevalent respiratory virus detected, particularly during exacerbations in children with $\mathrm{CF}<5$ years old. However, even though rhinoviral infections are likely to be one of the factors initiating the onset of CF lung disease, there is no effective targeted treatment. A better understanding of the innate immune responses by CF airway epithelial cells, the primary site of infection for viruses, is needed to identify why viral infections are more severe in CF. The aim of this review is to present the clinical impact of virus infection in both young children and adults with $\mathrm{CF}$, focusing on rhinovirus infection. Previous in vitro and in vivo investigations looking at the mechanisms behind virus infection will also be summarized. The review will finish on the potential of transcriptomics to elucidate the host-pathogen responses by CF airway cells to viral infection and identify novel therapeutic targets.

Keywords: cystic fibrosis, airway epithelium, rhinovirus, innate immune response, therapy, transcriptomic

\section{RESPIRATORY INFECTIONS IN THE CYSTIC FIBROSIS LUNG}

Chronic obstructive lung disease remains the primary cause of mortality and morbidity in CF (Cutting, 2015). The defective function of the Cystic Fibrosis Transmembrane Conductance Regulator (CFTR) gene initiates a lifelong cycle of neutrophilic inflammation, progressive bronchiectasis, mucus obstruction and recurrent microbial infection of the CF airway. These processes typically begin in the first years of life and lead to eventual lung failure during early adulthood. The CF airway environment is vulnerable to colonization by particular bacterial 
and fungi species including Haemophilus influenzae, Staphylococcus aureus, Aspergillus fumigatus, and Pseudomonas aeruginosa (Gangell et al., 2011). Infection by these common pathogens typically trigger neutrophilic responses, however, these fail to eradicate the infection and lead to a sustained release of oxidants and proteases, particularly neutrophil elastase (NE) (Hartl et al., 2007; Painter et al., 2008). This neutrophil-based inflammation has been associated with the progression of structural abnormalities specifically bronchiectasis and air trapping, from as early as 3 months of age (Mott et al., 2012; Sly et al., 2013).

In addition to colonization by bacteria and fungi, the CF airway will be infected with respiratory viruses and viral infections are a major cause of PEx in the pediatric CF population (Goffard et al., 2014; Dijkema et al., 2016). The significance of viral infections in CF has been identified by the advancements in molecular diagnostic technologies to detect virus (Wat, 2015). The prevalence of respiratory viruses during CF PEx can vary from $5 \%$ up to $60 \%$ (Billard et al., 2017) and include; rhinovirus $(\mathrm{RV})$, influenza A and B, respiratory syncytial virus (RSV), parainfluenza (PIV; Type 1-4), metapneumovirus, coronavirus and adenovirus (Waters and Ratjen, 2015; Flight and Jones, 2017). Earlier work suggested influenza viruses (A \& B) (Pribble et al., 1990; Hiatt et al., 1999) and RSV (Abman et al., 1991; Armstrong et al., 1998) were the major cause of PEx in CF. However, studies utilizing more sensitive virological methods in the last 5 years have comprehensively established RV as the most common respiratory virus detected in CF airway (Burns et al., 2012; Wark et al., 2012; Kieninger et al., 2013; Etherington et al., 2014; Dijkema et al., 2016; Stelzer-Braid et al., 2017). Despite numerous studies into the virology of CF airways, the mechanistic link between virus infection, airway inflammation and structural lung disease remains largely unknown. Further investigation into the interaction of these disease components is warranted.

\section{IMPACT OF RV INFECTION IN CF LUNG}

A member of the Picornaviridae family within the Enterovirus genus, RV features a positive sense single stranded RNA genome $\sim 7.2 \mathrm{~kb}$ in length. The airway epithelium is the primary site of RV infection and replication (Vareille et al., 2011). As reviewed by Palmenberg and Gern (2015), 11 viral proteins form the non-enveloped icosahedral structure. The external capsid proteins comprise of VP1, VP2, VP3, while VP4 is located between the interface of capsid protein and RNA genome. These capsid proteins feature a high degree of heterogeneity and consequently the significant antigenic diversity among RV has precluded vaccine development (Glanville and Johnston, 2015; Lewis-Rogers et al., 2017). Currently, there are more than 150 serotypes of RV, which have been classified into 3 species; RV-A, RV-B, and RV-C. Within RV-A and RV-B, strains are clustered into major and minor RV groups based upon their specificity for the intracellular adhesion molecule (ICAM-1) receptor or low-density lipoprotein receptor (LDLR), respectively (Palmenberg, 2017). Recently, the cell receptor for RV-C species has been putatively identified as cadherin related family member
3 (CDHR3), whose expression is largely confined to ciliated cells (Bochkov et al., 2015; Griggs et al., 2017; Palmenberg, 2017).

Rhinovirus infections occur all year round and children experience on average six to eight episodes per year (Worrall, 2011). Although the "common cold" is largely self-limiting, it still poses a burden on the activity and productivity of the general population (Stein, 2017). Additionally, RV infection has a more pronounced effect on vulnerable individuals such as children with CF, as summarized in Table 1. These include increased PEx (Asner et al., 2012), more severe respiratory symptoms (Burns et al., 2012; Wark et al., 2012), greater inflammation (Kieninger et al., 2013), reduced quality of life and hospitalization and prolonged antibiotic treatment (Smyth et al., 1995). Prevalence and symptoms of RV infection in patients with CF can vary between cohorts (reviewed by Billard et al., 2017), with some reporting similar rates of RV detection in both children with and without CF (de Almeida et al., 2010; Esposito et al., 2014), while others have reported significant correlations with disease progression in those with CF (Hiatt et al., 1999; van Ewijk et al., 2005). Other features such as age preference, RV serotype, viral load, impact on lung function were assessed in several studies. Susceptibility to particular RV serotype in children with CF requires further investigation due to inconsistent observations (de Almeida et al., 2010; Shah et al., 2015). RV load has been observed to be significantly higher in children with CF ( $>100$ times) when compared to healthy controls and children with asthma (>10 times; Kieninger et al., 2013). This study also illustrated that viral load was negatively correlated to pulmonary function (Kieninger et al., 2013). Cousin et al. (2016) observed that RV-induced PEx in children with CF resulted in failure of pulmonary function recovery for up to 6 weeks. An age preference for RV-associated CF exacerbations has also been reported for young children $<5$ years old (Stelzer-Braid et al., 2017). However, several other studies have detected a higher frequency of RV in upper and lower airway of adults with CF via screening of sputum and throat swabs (Etherington et al., 2014; Goffard et al., 2014). Adults with CF who have viral associated PEx have been shown to have worse lung function and require more days of intravenous antibiotic treatment (Flight et al., 2014; Goffard et al., 2014). Others have also reported that adult patients who are less responsive to treatment are readmitted for a subsequent exacerbation within a shorter time frame (Etherington et al., 2014). Finally, Flight et al. (2014) found that RV infection in adults is accompanied by an increased risk of PEx, prolonged antibiotic prescription, higher respiratory symptom scores and heightened level of C-reactive protein. As $\mathrm{RV}$ has a large clinical impact on those with CF, it is critical to elucidate how this virus alters host antiviral and inflammatory responses.

\section{AIRWAY EPITHELIUM AND RV INFECTION IN CF}

A pseudostratified epithelium lines the surface of the lung (trachea, primary bronchi, secondary bronchi, tertiary bronchi, and bronchioles) and is composed of several cell types including ciliated cells, basal cells, secretory cells and goblet cells. These 


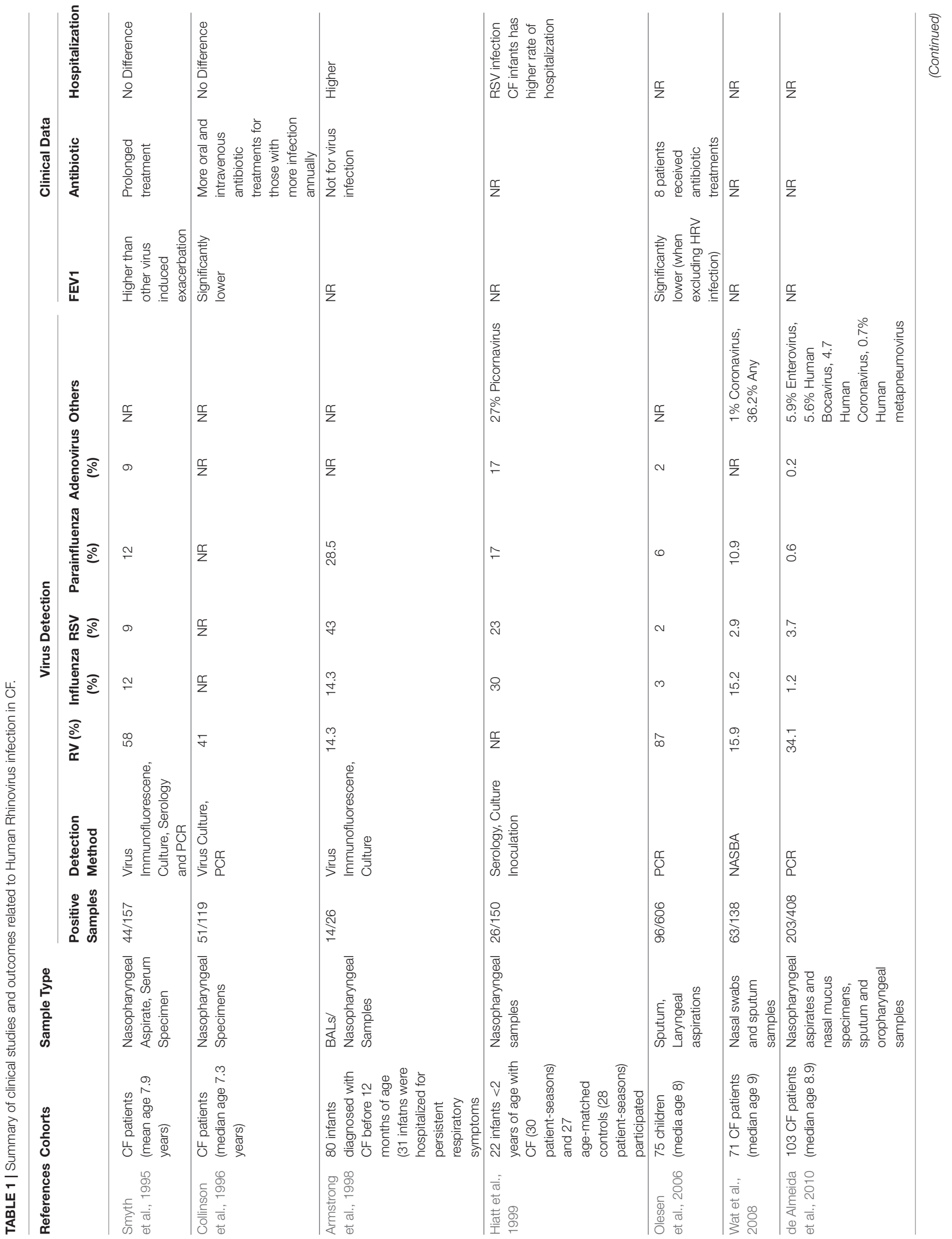




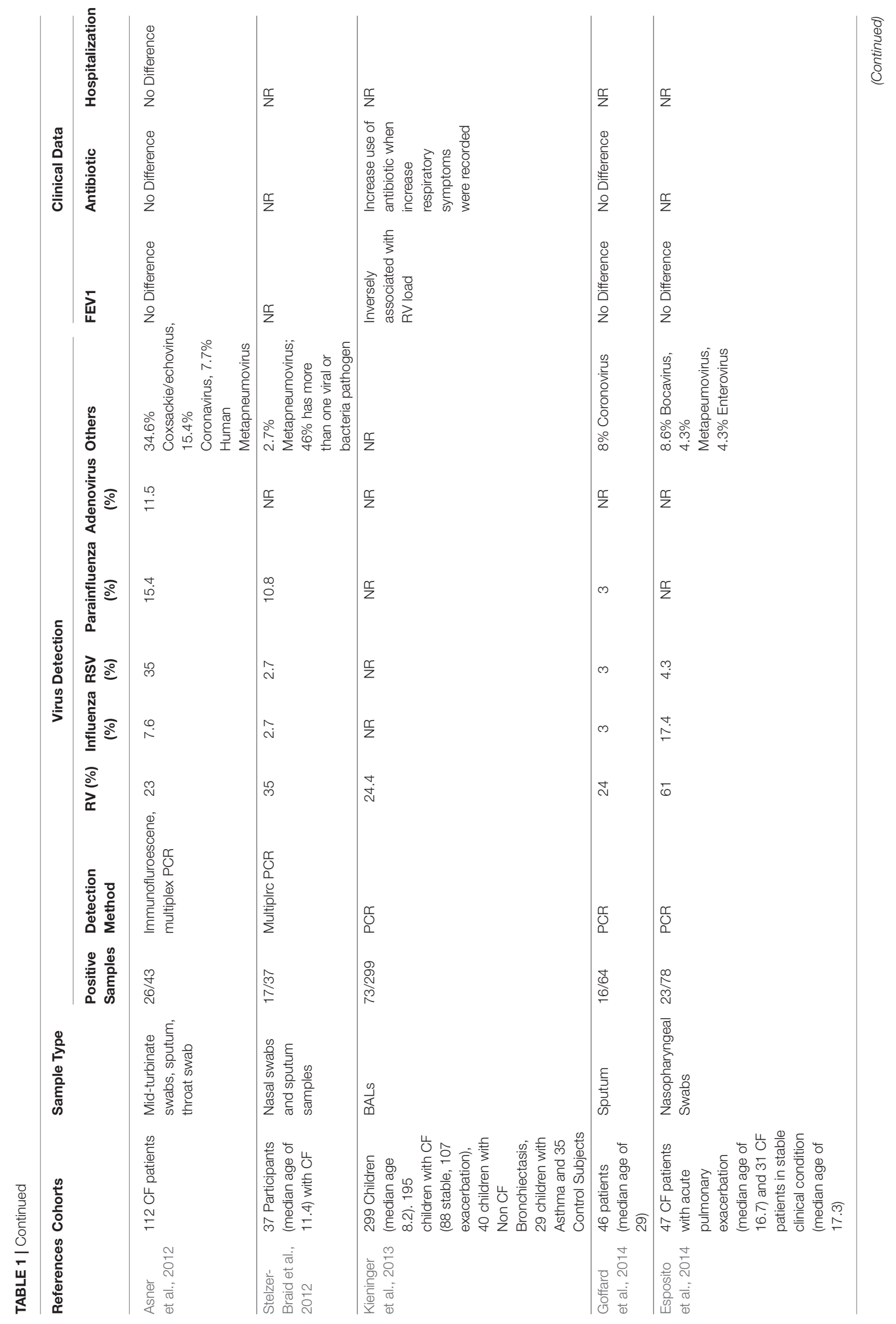




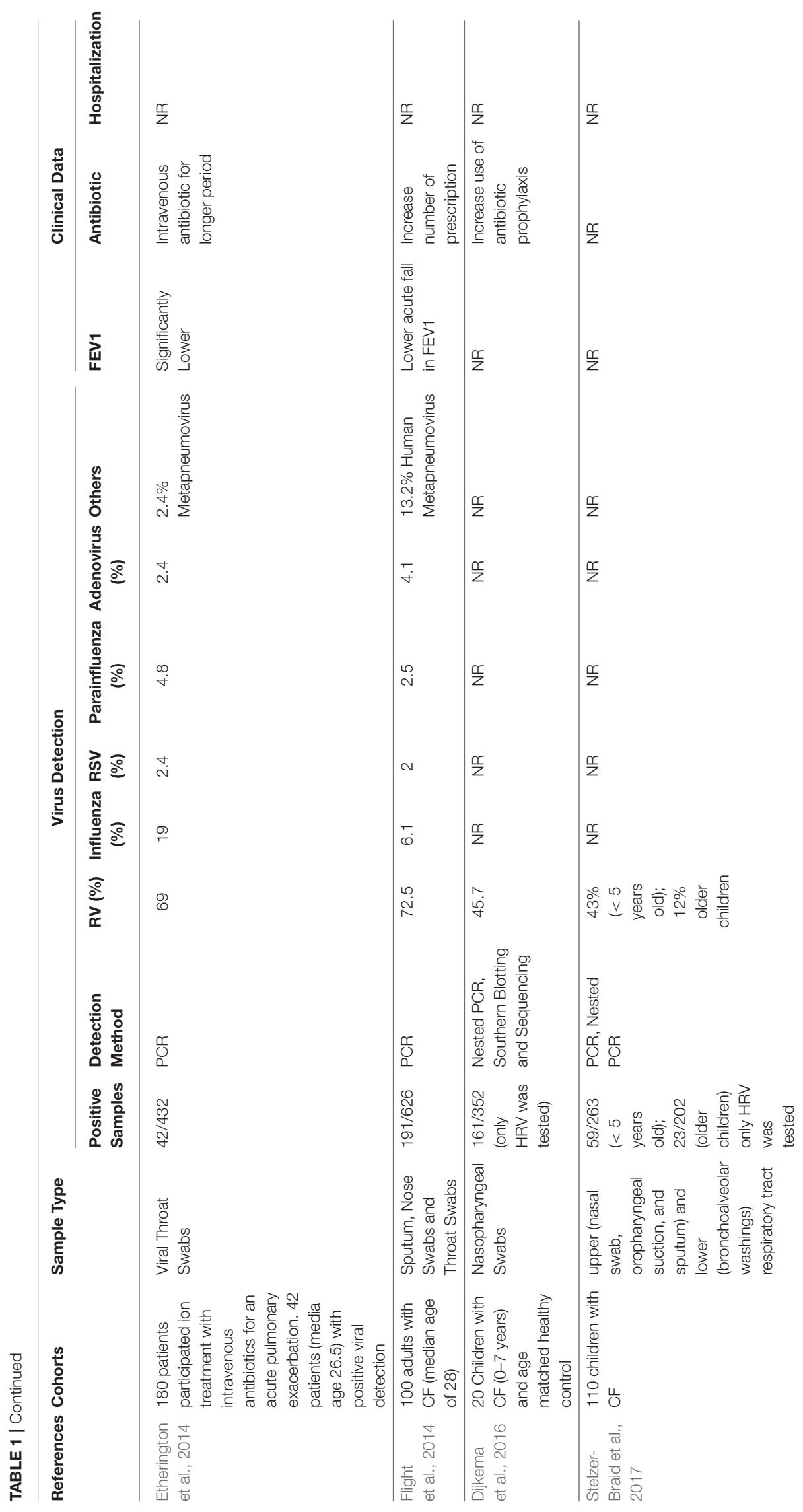


airway epithelial cells form the first point of contact with inhaled environmental insults, including respiratory viruses. To provide a physical barrier against particulates/pathogens from entering the lung tissue, numerous cell-cell connections are formed including tight junctions, adherent junctions, gap junctions, and desmosomes (Whitsett and Alenghat, 2015). To clear inhaled particles/pathogens, intraepithelial goblet cells, and submucosal glands mucous cells secret mucins. These large glycoproteins bind matter including microbes and allows effective cough clearance by the mucociliary escalator (Foster, 2015). Mucins are transported from the bronchioles to the trachea via beating cilia, expressed by airway epithelial cells of the luminal airway surface (Ma et al., 2018).

Perhaps more significantly for viral pathogens, the airway epithelium plays a crucial role in innate immunity. It has been suggested that the inflammatory responses induced by airway epithelial cells give rise to associated clinical symptoms (Jacobs et al., 2013). RVs can disrupt epithelial tight junctions including zona occludens 1 ( $\mathrm{ZO}-1)$ protein by stimulating the production of reactive oxygen species (ROS) during viral replication (Unger et al., 2014). Work utilizing airway epithelial cells in vitro have shown reduced expression of other tight junction proteins, loss of epithelial integrity, disruption of extracellular matrix and subepithelial fibrosis and induction of proangiogenic molecules which enhance angiogenesis and airway remodeling (Bossios et al., 2005; Leigh et al., 2008; Bochkov et al., 2010; Tacon et al., 2010; Yeo and Jang, 2010; Looi et al., 2018).

The uptake of RV via clathrin-dependent or -independent endocytosis or through micropinocytosis occurs when RV binds to its specific receptors. Upon binding and in a low- $\mathrm{pH}$ environment, uncoating of RVs occurs and the virus undergoes conformational changes. The loss of the protein capsid protein VP4, and the externalization of the hydrophobic N-terminal of VP1, facilitates RVs to cross the host cell membrane (Jacobs et al., 2013; Blaas and Fuchs, 2016). Following viral uncoating and membrane rupture, RV "pathogen-associated molecular patterns" (PAMP) are recognized by the host cell via interaction with pattern recognition receptors (PRRs) including; Toll like receptors (TLRs), C-type lectin receptors (CLRs), retinoic acidinducible gene 1 (RIG-I)-like receptors (RLRs), and nucleotidebinding oligomerization domain-like receptors (NLRs). The signaling pathways induced by TLRs and RLRs are typically host defense antiviral pathways as well as the production of antiviral substances, namely IFNs, B-defensins (Proud et al., 2004), and nitric oxide (Sanders et al., 1998). The airway epithelium also responds to RV infection by activating proinflammatory signaling pathways which trigger the release of chemokines and cytokines including IL-8, RANTES/CCL5, and granulocyte-macropahge colony-stimulating factor (GM-CSF), that in turn recruit neutrophils, esoinophils, natural killer cells (NK cells), and macrophages to the infected tissue. IL-6 has an important role in innate immune responses induced by RV infection and IL-6 production has been shown to be inversely correlated to cold symptoms scores and disease severity (Doyle et al., 2010). IL-15 exerts important antiviral and cytotoxic effects and is involved in the activation, differentiation, survival and recruitment of $\mathrm{NK}$ cells and $\mathrm{CD} 8+\mathrm{T}$ cells (Jayaraman et al.,
2014). IL-8 has been associated with RV infection as well as cold symptom scores (Gern et al., 2002). Furthermore, it has also been associated with neutrophilic infiltration in sputum (Gern et al., 2000). Taken together, it is evident that innate immune signaling induced by the airway epithelium is essential for effective antiviral responses.

However, in many chronic airway diseases including CF, antiviral responses are defective. Due to the pre-existing genetic defect, normal functions of the CF airway epithelium are often disrupted. As the primary site for virus entry and replication during viral infection, understanding the consequence that lack of CFTR function has on pathophysiology during virus infection is critical for effective disease management. Relevant in vitro experimental studies investigating RV infection in CF epithelium have been summarized in Table 2. Most studies performed to date assessed cells obtained from adult CF cohorts who had significant disease and structural lung damage. These studies report similar levels of interferon production post infection despite higher viral load being detected (Chattoraj et al., 2011; Dauletbaev et al., 2015). Studying cells from pediatric CF cohorts may generate more relevant data and potentially reveal new insights into early life RV infections that could be exploited therapeutically. Also important is the level of pro-inflammatory cytokines produced by CF epithelium following RV infection. Many studies have reported similar level of IL-8, IL-6, type I, and III IFN production, while others reported higher level of production dependent on virus strain and infectious titer (Table 2). These contradictory observations may be due in part to the age of patients involved, disease severity, RV strain, dose, and length of infection. Most studies to date including ours have focused on specific host response targets at the gene or protein level which might not reflect the global innate immune changes during RV infection. The translation of such a targeted approach would be the identification of a single molecule to address a single pathway and ultimately target one downstream effect such as the production of a single cytokine. However, knowing that the interaction of RV and the airway is multifaceted, an alternative approach that addresses this complexity is needed.

\section{PAST AND CURRENT THERAPIES}

To date, there have been no studies performed that have focused on potential treatments for RV infection in CF individuals. As RV continues to be the most prevalently detected virus in the all individuals including CF airway, additional evidence is needed to specify its connection with the existing factors such as lack of CFTR and airway inflammation through molecular intermediates and cellular signaling pathways. Common antiinflammatories including oral corticosteroids and high-dose ibuprofen are unsuitable for treatment in infants and preschool children due to their long-term side effects (Lai et al., 2000; Fennell et al., 2007). Azithromycin may have some interesting antiviral properties, specifically in reducing RV replication via amplification of the IFN pathway-mediated antiviral responses (Schögler et al., 2014). Nevertheless, clinical studies are necessary 


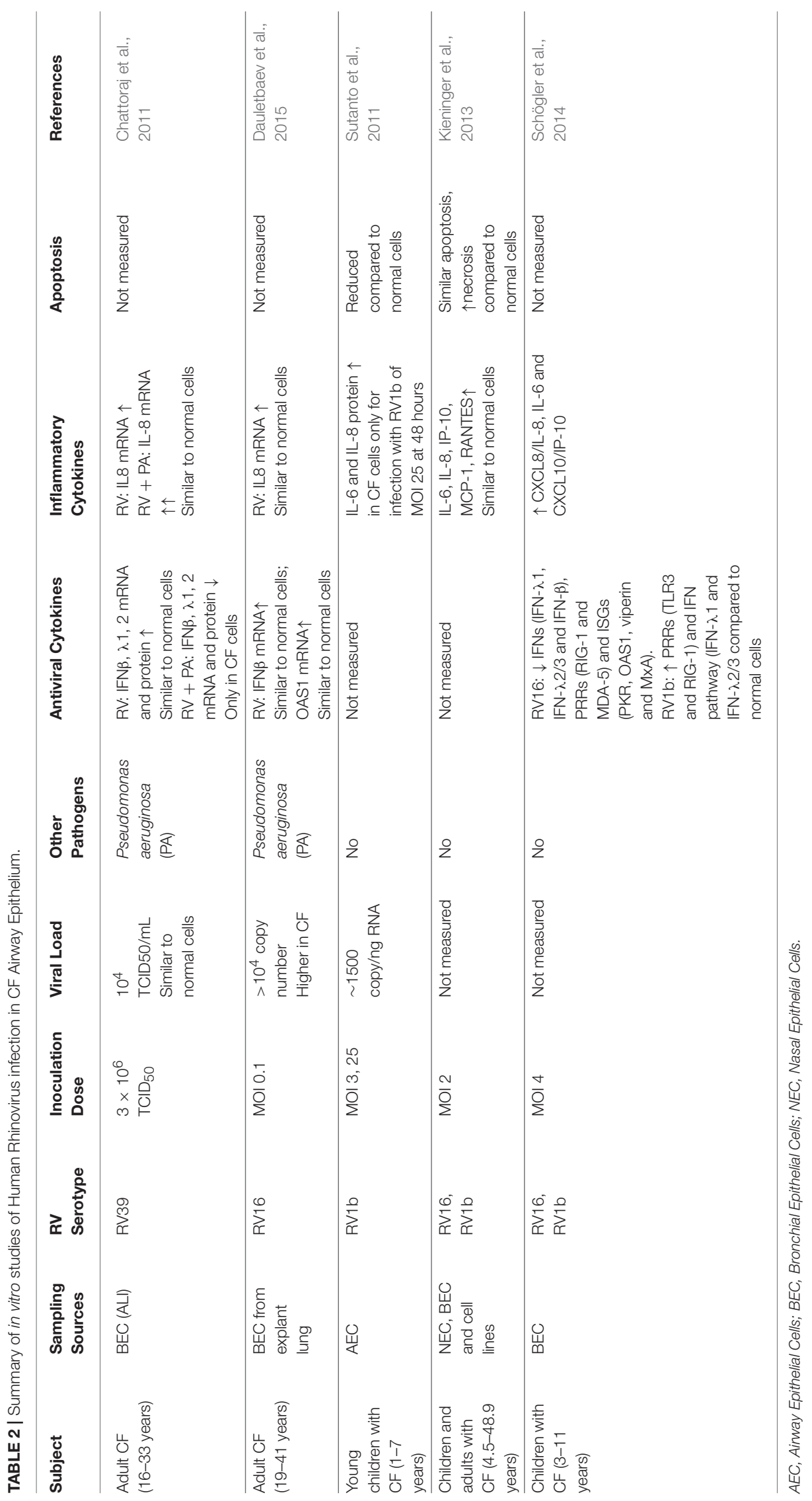


to elucidate the clinical impact of azithromycin against RVinduced PEx in patients with CF. Vaccination is an important part of CF clinical care, however vaccine development for RV has been rather challenging due to the wide range of antigenic diversity of more than 150 serotypes of RV across three different strains. Technical difficulties in producing sufficient amounts of antigen against multiple RV serotypes using animal models (as reviewed in Del Vecchio et al., 2015) also remains a challenge and as result, the development of a long-lasting RV vaccine has not been successful. This has been further compounded by the lack of a suitable model (other than human) that is fully permissive to RV infection as well as insufficient clinical data to identify and prioritize dominant RV serotypes. In addition, no suitable animal models for CF exhibit complete spectrum of CF phenotype besides CF pig and ferret which are strictly limited for research use (as reviewed in Rosen et al., 2018).

Since vaccination is unavailable, other approaches have been explored in healthy and disease cohorts other than CF. An early approach by Turner et al. (1999) aimed to prevent HRV binding to its receptors via administration of inhaled recombinant soluble ICAM-1 (Tremacamra). Although the reduction in symptom severity and viral shedding were promising, the high costs and dosing regimen recommended ( 6 times daily) made translation of this therapy into the clinical setting prohibitive (Turner et al., 1999). Targeting viral replication has perhaps been the highest priority in past therapeutic development, where capsidbinding drugs bind to the hydrophobic "pocket" of the viral capsid (reviewed in McKinlay et al., 1992). Pleconaril and Pirodavir were discontinued due to unforeseen side effects and drug efficacy. Reformulated Pleconaril and Vapendavir have completed clinical trials although results have yet to be published [ClinicalTrials.gov (NCT00394914 \& NCT01175226)]. A recently discovered compound IMP-1088 offers more promise (Mousnier et al., 2018). This molecule was shown to inhibit human $\mathrm{N}$ myristoyltransferases NMT1 and NMT2, prevent virus assembly and suppress RV replication and infection across various RV strains without inducing cytotoxicity. However, most of this work was demonstrated using cell lines or adult primary cells and further assessment of IMP-1088 on primary cells from young children with CF is necessary. The outcome of such studies would be informative as to whether this compound exerts similar efficacy across all cohorts, as more than 30 polymorphic DNA loci associated with host variation in gene expression called responsereQTLs to rhinovirus infection has been previously reported (Çalişkan et al., 2015).

Alternatively, the roles of type I IFN administration in enhancing the primary antiviral signaling pathway of innate immunity have also been assessed. Early studies involving the prophylactic administration of IFN- $\alpha 2$ or IFN- $\beta$ were found to demonstrate a reduction in number of RV-induced episodes but no difference in symptom severity or duration (Farr et al., 1984; Hayden et al., 1986; Monto et al., 1986; Sperber et al., 1988). Multiple side effects from high dose administration of IFNs, including nasal bleeding, transient leukopenia and sore throat have also been reported (Sperber et al., 1988). A more recent study assessed low dose IFN- $\beta$ administration and although antiviral activity was enhanced, it did not aid in reducing cold symptoms of viral induced exacerbations asthma cohorts (Djukanović et al., 2014). Ruuskanen et al. (2014) also suggested that short-term subcutaneous pegylated IFN- $\alpha$ in combination with oral ribavirin treatment rapidly decreased RV RNA in recurrent or chronic rhinovirus infection in immunocompromised patients.

Alternative therapies have not been thoroughly assessed in CF cohorts. While ongoing clinical trials are comprehensive in evaluating the efficacy of CFTR potentiators and correctors for application on mutation specific patients, improvements in infection and inflammation therapies would be highly desirable for all individuals with CF. Indeed, Ivacaftor has been found to reduce sputum $P$. aeruginosa density ( $>60$-fold) and airway inflammation significantly (Hisert et al., 2017). Whether improvements in CFTR folding or function will enhance antiviral responses in children with CF warrant further investigation. Multi-target drug design also holds potential and could be employed to exert both antiviral and anti-inflammation effects. Understanding how host anti-viral and inflammatory responses differ in CF airways, particularly young children, is critical in facilitating the development of new therapeutic treatments that can limit CF disease progression.

\section{NEW THERAPEUTIC FOR RV INFECTIONS}

Current therapies directed at RV are mainly focusing on specific viral proteins or inhibition of viral cycle. However, some of these drugs are not effective on drug-resistant viral strains. The current review proposes an alternative approach that focuses on host cellular pathways and factors. To expedite novel therapeutic strategies, investigation on how cellular signaling pathways can be altered by RV infection and how these alterations can be manipulated by new compounds or drugs are crucial for new therapeutic development. The current field of system biology and adoption of high-throughput technologies through transcriptomics not only facilitates characterization of the hostpathogen interaction in a more comprehensive manner, but also aids in understanding how developed and repurposed compounds exert their antiviral properties on RV infection in CF patients.

Knowing viruses can manipulate the host signaling processes and thus altering the host-pathogens interactions (Christiaansen et al., 2015), evaluating the global changes in gene expression during infection via employing gene/transcriptomics could elucidate crucial messages for therapeutic target identification. Transcriptomics is used to study the total RNA output of a cell. Early transcriptomic analyses were performed using microarrays which have customized probes, while current transcriptomic analyses rely on high-throughput RNA sequencing which capture global transcriptome (Mortazavi et al., 2008). These techniques allow analysis for "all molecules" regulated at the gene level. By illustrating their interaction within the cells and the complexities of host-pathogen interactions, enhancing or diminishing specific molecules as well as precise characterization of specific targets can be a more promising therapeutic approach (as reviewed in Cesur and Durmuş, 2018). Generally, computational approaches 
are used to organize or manage these data sets and interpret the biological inference, including network analysis (such as InnateDB, NetworkAnlayst, and Cytoscape) and pathway analysis (such as Reactome, Kegg Pathway, and Pantherdb).

In the context of host-viral interaction, transcriptomic analysis has been successfully applied to identify the uncharacterized isoforms from wild-type dengue infected host RNA from human hepatoma cells. The authors demonstrated that infection with wild-type dengue virus elicited a different host response compared to infection with a vaccine sensitive strain, highlighting the potential of strain-specific responses (Sessions et al., 2013). Transcriptional profiling of blood specimens from

\section{Sample Collection}

- Bronchial epithelial samples from healthy individual and children with CF

- Establishment of cell culture

- Virus Infection

- RNA Extraction/Purification

\section{RNA sequencing}

- Library preparation

- Illumina high-throughput strand-specific transcriptome sequencing

\section{Preprocessing}

- Quality control before alignment

- Alignment (STAR, HISAT) and assembly (ht-seq, Stringtie)

- Mapping to reference genome

\section{Transcriptomic Analysis}

- Data filtering, normalization and variance correction

- Differentially expression analysis (DESeq2, EdgeR, Kallisto)

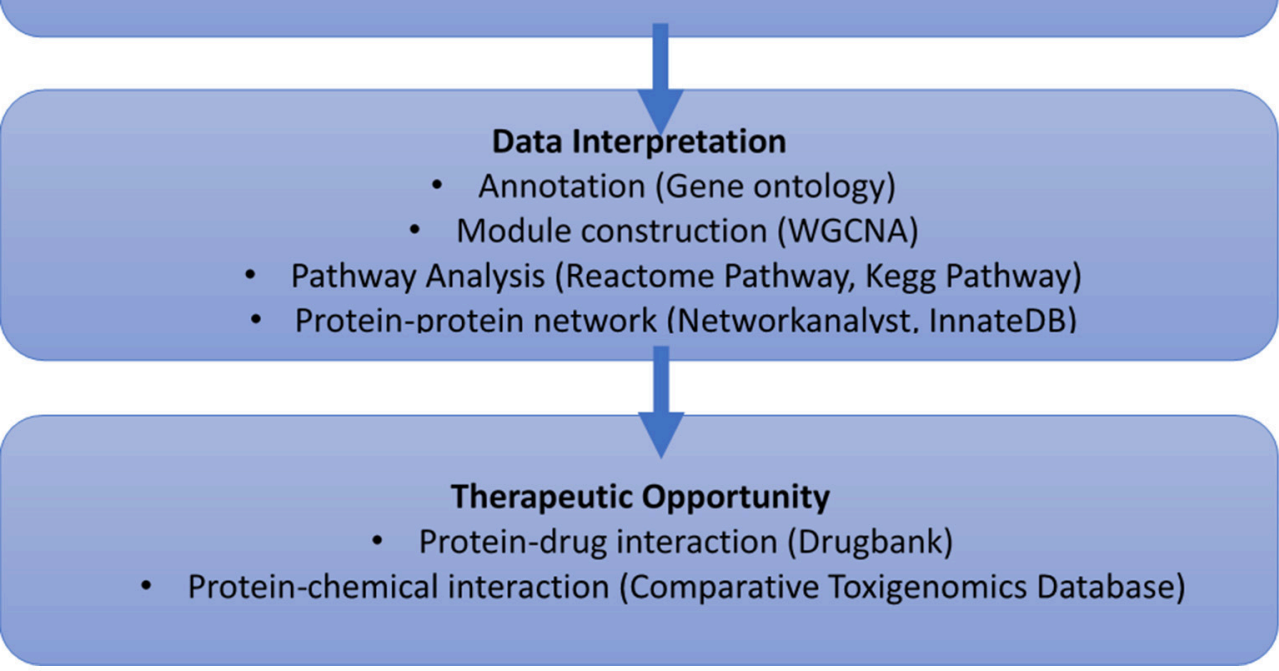

FIGURE 1 | Proposed workflow using transcriptomics to elucidate future treatment for cold virus infection in CF. 
symptomatic and asymptomatic patients with RV infection have revealed that individuals with active infection demonstrate a robust transcriptional signature of immune-related genes (Heinonen et al., 2016). In other disease settings including asthma and allergic rhinitis, transcriptomic responses of human respiratory cells to surrogate RV infection [Poly(I:C) stimulation] have potentially identified disease-specific signatures (Wagener et al., 2014). Therefore, it is imperative to assess the global transcript expression and investigate the host-viral interaction, given that $\mathrm{CF}$ is a defined genetic disease condition and live RV infection can truly represent an active infection which might involve modification of the host response. This approach is not only applied to protein-coding RNA but also provide insights to critical non-coding RNA such as short non-coding RNAs (miRNAs) and long non-coding RNAs (lncRNAs) which are key regulators for modulation of gene expression (Delpu et al., 2016).

Mapping genes on a complete network allows identification of key hub genes and central genes with high connectivity which exert large effects on signal transduction. Molecular network analysis also allows enrichment of functional modules to identify which area group of genes are cooperatively working together to perform specific biological function and could be associated with disease setting (reviewed by Csermely et al., 2013). Some examples include, the identification of 16 strongly connected hub genes as potential antifungal drug targets against Candida albicans (Altwasser et al., 2012), the identification of new key genes for type 1 diabetes (Safari-Alighiarloo et al., 2016) as well as certain cancers (Zaman et al., 2013; Jin et al., 2015). Moreover, omics data has discovered disease modules and revealed substantial inter-patient heterogeneity, highlighting the potential importance of customize treatments to conditions. Numerous algorithms have been introduced to identify disease modules, including ModuleDiscoverer that identified a rodent model of non-alcoholic steatohepatitis (NASH), as well as a severe form of non-alcoholic fatty liver disease (NAFLD) (Vlaic et al., 2018). To maximize the efficacy and treatment outcome, patient individual characteristics, including their genetic profile needs to be considered. Although using biological network analysis can expedite the drug discovery process, the timeline from target identification to clinic application can still be lengthy.

An alternative strategy is to explore drug repurposing. Integrated analysis of disease-gene profiles, pathway analysis, and mining of FDA approved drug databases can be carried out to identify correlations of common pathways with certain compounds or molecules at the network level. Successful examples of drug repurposing based on transcriptomic analyses include the identification of topiramate for the treatment of inflammatory bowel disease (IBD) and cimetidine for the treatment of lung adenocarcinoma (Dudley et al., 2011; Sirota et al., 2011). Using a large-scale expression signature, Lee et al. (2016) have also identified that ivermectin, trifluridine, astemizole, amlodipine, maprotiline, apomorphine, mometasone, and nortriptyline show significant anti-proliferative activity against glioblastoma. With the recent establishment of ImmPort, a data repository that promotes research dataset repurposing (Bhattacharya et al., 2018), the identification of novel targets and repurposed drugs that target these has been accelerated further. Currently, there is paucity of data in CF-related RVtherapy given its impact on CF lung disease and thus new interventions are urgently required. The strategy to repurpose already approved drugs could advance antiviral therapies by reducing cost and improving and quality of life for affected individuals.

\section{CONCLUSION}

RV infection remains a significant cause of pulmonary exacerbation in CF. There has been little investigation into antiviral therapies in CF especially in young children who are more susceptible to these types of infection. However, modern virological procedures and omic technologies now facilitate more in-depth studies of the genes and molecular pathways involved in aberrant CF antiviral responses to RV. We propose transcriptomics could be leveraged to elucidate future therapeutic intervention for treatment of rhinovirus infection in CF. For example, a global gene expression profile of bronchial epithelial cells from patients with $\mathrm{CF}$, under baseline conditions and after RV infection will be profiled following next-generation RNA sequencing (Figure 1). Sequences can be aligned and mapped to already available reference genomes to identify differentially expressed genes pre- and post-infection. The identified genes could then be annotated using online repositories or libraries to investigate their enriched functional biological pathways. Moreover, networks or subnetworks can then be constructed by mapping identified genes to explore their relationship using curated protein-protein interaction databases. Therapeutic opportunities can also identify by exploring protein-protein interaction and protein-transcription factor, protein-drug interaction as well as chemical interaction databases. Finally, monolayer cell cultures which have previously been found to be more susceptible for RV infection (Bochkov et al., 2010) represent an oversimplified model for the multicellular interactions of epithelial (ciliated cells, goblet cells) and immune cells (dendritic cells, neutrophils). Indeed, functional validation utilizing human in vitro $3 \mathrm{D}$ airway models (Boda et al., 2018) will be needed to further elucidate to host-pathogen interactions. The emergence of single cell transcriptomics could be used to compliment 3D airway models and accelerate progress in this new era of scientific research. Overall, the advancement of these promising tools should aid in expediting new therapeutic intervention in this sphere.

\section{AUTHOR CONTRIBUTIONS}

K-ML, LG, and AK conceptualized the contents of the manuscript. K-ML wrote the first draft of the manuscript. K-ML, LG, TL, SS, and AK contributed to the drafting and editing of the manuscript. WAERP, AusREC, and AREST CF approved the final submission of the manuscript. 


\section{ACKNOWLEDGMENTS}

The members of Western Australian Epithelial Research Program (WAERP) are: AK, SS, Darryl A. Knight, Elizabeth KicicStarcevich, LG, Marc Padros-Goosen, Ee-Lyn Tan, Erika N. Sutanto. Kevin Looi, Jessica Hillas, Thomas Iosifidis, Nicole C. Shaw, Samuel T. Montgomery, K-ML, Kelly M. Martinovich, Francis J. Lannigan, Ricardo Bergesio, Bernard Lee, Shyan Vijaya-Sekeran, Paul Swan, Mairead Heaney, Ian Forsyth, Tobias Schoep, Alexander Larcombe, Monica Hunter, Kate McGee, Nyssa Millington. The full membership of the Australian Respiratory Early Surveillance Team for Cystic Fibrosis (AREST $\mathrm{CF}$ ) is available at www.arestcf.org. The Australian Respiratory

\section{REFERENCES}

Abman, S. H., Ogle, J. W., Harbeck, R. J., Butler-Simon, N., Hammond, K. B., and Accurso, F. J. (1991). Early bacteriologic, immunologic, and clinical courses of young infants with cystic fibrosis identified by neonatal screening. J. Pediatr. 119, 211-217. doi: 10.1016/S0022-3476(05) 80729-2

Altwasser, R., Linde, J., Buyko, E., Hahn, U., and Guthke, R. (2012). Genomewide scale-free network inference for Candida albicans. Front. Microbiol. 3:51. doi: 10.3389/fmicb.2012.00051

Armstrong, D., Grimwood, K., Carlin, J. B., Carzino, R., Hull, J., Olinsky, A., et al. (1998). Severe viral respiratory infections in infants with cystic fibrosis. Pediatr. Pulmonol. 26, 371-379. doi: 10.1002/(SICI)1099-0496(199812)26:6<371::AIDPPUL1>3.0.CO;2-N

Asner, S., Waters, V., Solomon, M., Yau, Y., Richardson, S. E., Grasemann, H., et al. (2012). Role of respiratory viruses in pulmonary exacerbations in children with cystic fibrosis. J. Cyst. Fibros. 11, 433-439. doi: 10.1016/j.jcf.2012. 04.006

Bhattacharya, S., Dunn, P., Thomas, C. G., Smith, B., Schaefer, H., Chen, J., et al. (2018). ImmPort, toward repurposing of open access immunological assay data for translational and clinical research. Sci. Data 5:180015. doi: 10.1038 /sdata.2018.15

Billard, L., Le Berre, R., Pilorgé, L., Payan, C., Héry-Arnaud, G., and Vallet, S. (2017). Viruses in cystic fibrosis patients' airways. Crit. Rev. Microbiol. 43, 690-708. doi: 10.1080/1040841X.2017.1297763

Blaas, D., and Fuchs, R. (2016). Mechanism of human rhinovirus infections. Mol. Cell. Pediatr. 3:21. doi: 10.1186/s40348-016-0049-3

Bochkov, Y. A., Hanson, K. M., Keles, S., Brockman-Schneider, R. A., Jarjour, N. N., and Gern, J. E. (2010). Rhinovirus-induced modulation of gene expression in bronchial epithelial cells from subjects with asthma. Mucosal Immunol. 3, 69-80. doi: 10.1038/mi.2009.109

Bochkov, Y. A., Watters, K., Ashraf, S., Griggs, T. F., Devries, M. K., Jackson, D. J., et al. (2015). Cadherin-related family member 3, a childhood asthma susceptibility gene product, mediates rhinovirus $\mathrm{C}$ binding and replication. Proc. Natl. Acad. Sci. U.S.A. 112, 5485-5490. doi: 10.1073/pnas.1421 178112

Boda, B., Benaoudia, S., Huang, S., Bonfante, R., Wiszniewski, L., Tseligka, E. D., et al. (2018). Antiviral drug screening by assessing epithelial functions and innate immune responses in human 3D airway epithelium model. Antiviral Res. 156, 72-79. doi: 10.1016/J.ANTIVIRAL.2018.06.007

Bossios, A., Psarras, S., Gourgiotis, D., Skevaki, C. L., Constantopoulos, A. G., Saxoni-Papageorgiou, P., et al. (2005). Rhinovirus infection induces cytotoxicity and delays wound healing in bronchial epithelial cells. Respir. Res. 6:114. doi: 10.1186/1465-9921-6-114

Burns, J. L., Emerson, J., Kuypers, J., Campbell, A. P., Gibson, R. L., McNamara, S., et al. (2012). Respiratory viruses in children with cystic fibrosis: viral detection and clinical findings. Influenza Other Respir. Viruses 6, 218-223. doi: 10.1111/j.1750-2659.2011.00292.x
Epithelium Consortium (AusREC) acknowledges the following members; AK, SS, Elizabeth Kicic-Starcevich, LG, Erika N. Sutanto, Kevin Looi, Jessica Hillas, Thomas Iosifidis, Nicole C. Shaw, Samuel T. Montgomery, K-ML, Kelly M. Martinovich, Matthew W.-P. Poh, Daniel R. Laucirica, Craig Schofield, Samantha McLean, Katherine Landwehr, Emma de Jong, Nigel Farrow, Eugene Roscioli, David Parsons, Darryl A. Knight, Christopher Grainge, Andrew T. Reid, Su-Kim Loo, and Punnam C. Veerati. This work was supported by grants from the National Health and Medical Research Council of Australia (NHMRC; APP1069101 and APP1142505) and United States Cystic Fibrosis Foundation (\#STICK15A0). SS is a NHMRC Practitioner Fellow. LG is a NHMRC Peter Doherty Fellow.
Çalişkan, M., Baker, S. W., Gilad, Y., and Ober, C. (2015). Host genetic variation influences gene expression response to rhinovirus infection. PLoS Genet. 11:e1005111. doi: 10.1371/journal.pgen.1005111

Cesur, M. F., and Durmuş, S. (2018). "Systems biology modeling to study pathogen-host interactions," in Host-Pathogen Interactions. Methods in Molecular Biology, eds C. Medina and F. López-Baena (New York, NY: Human Press), 97-112. doi: 10.1007/978-1-4939-7604-1_10

Chattoraj, S. S., Ganesan, S., Jones, A. M., Helm, J. M., Comstock, A. T., BrightThomas, R., et al. (2011). Rhinovirus infection liberates planktonic bacteria from biofilm and increases chemokine responses in cystic fibrosis airway epithelial cells. Thorax 66, 333-339. doi: 10.1136/thx.2010.151431

Christiaansen, A., Varga, S. M., and Spencer, J. V. (2015). Viral manipulation of the host immune response. Curr. Opin. Immunol. 36, 54-60. doi: 10.1016/j.coi.2015.06.012

Collinson, J., Nicholson, K. G., Cancio, E., Ashman, J., Ireland, D. C., Hammersley, V., et al. (1996). Effects of upper respiratory tract infections in patients with cystic fibrosis. Thorax 51, 1115-1122. doi: 10.1136/thx.51.11.1115

Cousin, M., Molinari, N., Foulongne, V., Caimmi, D., Vachier, I., Abely, M., et al. (2016). Rhinovirus-associated pulmonary exacerbations show a lack of FEV 1 improvement in children with cystic fibrosis. Influenza Other Respir. Viruses 10, 109-112. doi: 10.1111/irv.12353

Csermely, P., Korcsmáros, T., Kiss, H. J. M., London, G., and Nussinov, R. (2013). Structure and dynamics of molecular networks: a novel paradigm of drug discovery: a comprehensive review. Pharmacol. Ther. 138, 333-408. doi: 10.1016/j.pharmthera.2013.01.016

Cutting, G. R. (2015). Cystic fibrosis genetics: from molecular understanding to clinical application. Nat. Rev. Genet. 16, 45-56. doi: 10.1038/nrg3849

Dauletbaev, N., Das, M., Cammisano, M., Chen, H., Singh, S., Kooi, C., et al. (2015). Rhinovirus load is high despite preserved interferon- $\beta$ response in cystic fibrosis bronchial epithelial cells. PLoS ONE 10:e0143129. doi: 10.1371/journal.pone.0143129

de Almeida, M. B., Zerbinati, R. M., Tateno, A. F., Oliveira, C. M., Romão, R. M., Rodrigues, J. C., et al. (2010). Rhinovirus C and respiratory exacerbations in children with cystic fibrosis. Emerg. Infect. Dis. 16, 996-999. doi: 10.3201/eid1606.100063

Del Vecchio, A. M., Branigan, P. J., Barnathan, E. S., Flavin, S. K., Silkoff, P. E., and Turner, R. B. (2015). Utility of animal and in vivo experimental infection of humans with rhinoviruses in the development of therapeutic agents for viral exacerbations of asthma and chronic obstructive pulmonary disease. Pulm. Pharmacol. Ther. 30, 32-43. doi: 10.1016/J.PUPT.2014.10.005

Delpu, Y., Larrieu, D., Gayral, M., Arvanitis, D., Dufresne, M., Cordelier, P., et al. (2016). "Noncoding RNAs: clinical and therapeutic applications," in Drug Discovery in Cancer Epigenetics, eds G. Egger and P. Arimondo (Academic Press), 305-326. doi: 10.1016/B978-0-12-802208-5.00012-6

Dijkema, J. S., Ewijk, B. E., van, Wilbrink, B., Wolfs, T. F. W., Kimpen, J. L. L., and Ent, C. K., van der (2016). Frequency and duration of rhinovirus infections in children with cystic fibrosis and healthy controls: a longitudinal cohort study. Pediatr. Infect. Dis. J. 35, 379-383. doi: 10.1097/INF.0000000000001014 
Djukanović, R., Harrison, T., Johnston, S. L., Gabbay, F., Wark, P., Thomson, N. C., et al. (2014). The effect of inhaled IFN- $\beta$ on worsening of asthma symptoms caused by viral infections. A randomized trial. Am. J. Respir. Crit. Care Med. 190, 145-154. doi: 10.1164/rccm.201312-2235OC

Doyle, W. J., Casselbrant, M. L., Li-Korotky, H.-S., Doyle, A. P. C., Lo, C.-Y., Turner, R., et al. (2010). The interleukin 6-174 C/C genotype predicts greater rhinovirus illness. J. Infect. Dis. 201, 199-206. doi: 10.1086/649559

Dudley, J. T., Sirota, M., Shenoy, M., Pai, R. K., Roedder, S., Chiang, A. P., et al. (2011). Computational repositioning of the anticonvulsant topiramate for inflammatory bowel disease. Sci. Transl. Med. 3:96ra76. doi: 10.1126/scitranslmed.3002648

Esposito, S., Daleno, C., Scala, A., Castellazzi, L., Terranova, L., Sferrazza Papa, S., et al. (2014). Impact of rhinovirus nasopharyngeal viral load and viremia on severity of respiratory infections in children. Eur. J. Clin. Microbiol. Infect. Dis. 33, 41-48. doi: 10.1007/s10096-013-1926-5

Etherington, C., Naseer, R., Conway, S. P., Whitaker, P., Denton, M., and Peckham, D. G. (2014). The role of respiratory viruses in adult patients with cystic fibrosis receiving intravenous antibiotics for a pulmonary exacerbation. J. Cyst. Fibros. 13, 49-55. doi: 10.1016/j.jcf.2013.06.004

Farr, B. M., Gwaltney, J. M., Adams, K. F., and Hayden, F. G. (1984). Intranasal interferon- $\alpha 2$ for prevention of natural rhinovirus colds. Antimicrob. Agents Chemother. 26, 31-34. doi: 10.1128/AAC.26.1.31

Fennell, P. B., Quante, J., Wilson, K., Boyle, M., Strunk, R., and Ferkol, T. (2007). Use of high-dose ibuprofen in a pediatric cystic fibrosis center. J. Cyst. Fibros. 6, 153-158. doi: 10.1016/j.jcf.2006.06.003

Flight, W., and Jones, A. (2017). The diagnosis and management of respiratory viral infections in cystic fibrosis. Expert Rev. Respir. Med. 11, 221-227. doi: 10.1080/17476348.2017.1288102

Flight, W. G., Bright-Thomas, R. J., Tilston, P., Mutton, K. J., Guiver, M., Morris, J., et al. (2014). Incidence and clinical impact of respiratory viruses in adults with cystic fibrosis. Thorax 69, 247-253. doi: 10.1136/thoraxjnl-2013-204000

Foster, W. M. (2015). "Mucociliary function," in Comparative Biology of the Normal Lung, 2nd Edn., ed R. A. Parent (Academic Press), 561-579. doi: 10.1016/B978-0-12-404577-4.00029-1

Gangell, C. L., Gard, S. E., Douglas, T. A., Park, J., de Klerk, N. H., Keil, $\mathrm{T}$, et al. (2011). Inflammatory responses to individual microorganisms in the lungs of children with cystic fibrosis. Clin. Infect. Dis. 53, 425-432. doi: $10.1093 / \mathrm{cid} / \mathrm{cir} 399$

Gern, J. E., Martin, M. S., Anklam, K. A., Shen, K., Roberg, K. A., Carlson-Dakes, K. T., et al. (2002). Relationships among specific viral pathogens, virus-induced interleukin-8, and respiratory symptoms in infancy. Pediatr. Allergy Immunol. 13, 386-393. doi: 10.1034/j.1399-3038.2002.01093.x

Gern, J. E., Vrtis, R., Grindle, K. A., Swenson, C., and Busse, W. W. (2000). Relationship of upper and lower airway cytokines to outcome experimental rhinovirus infection. Am. J. Respir. Crit. Care Med. 162, 2226-2231. doi: 10.1164/ajrccm.162.6.2003019

Glanville, N., and Johnston, S. L. (2015). Challenges in developing a cross-serotype rhinovirus vaccine. Curr. Opin. Virol. 11, 83-88. doi: 10.1016/j.coviro.2015.03.004

Goffard, A., Lambert, V., Salleron, J., Herwegh, S., Engelmann, I., Pinel, C., et al. (2014). Virus and cystic fibrosis: rhinoviruses are associated with exacerbations in adult patients. J. Clin. Virol. 60, 147-153. doi: 10.1016/j.jcv.2014.02.005

Griggs, T. F., Bochkov, Y. A., Basnet, S., Pasic, T. R., Brockman-Schneider, R. A., Palmenberg, A. C., et al. (2017). Rhinovirus C targets ciliated airway epithelial cells. Respir. Res. 18:84. doi: 10.1186/s12931-017-0567-0

Hartl, D., Latzin, P., Hordijk, P., Marcos, V., Rudolph, C., Woischnik, M., et al. (2007). Cleavage of CXCR1 on neutrophils disables bacterial killing in cystic fibrosis lung disease. Nat. Med. 13, 1423-1430. doi: 10.1038/nm1690

Hayden, F. G., Albrecht, J. K., Kaiser, D. L., and Gwaltney, J. M. (1986). Prevention of natural colds by contact prophylaxis with intranasal alpha 2 -interferon. $N$. Engl. J. Med. 314, 71-75. doi: 10.1056/NEJM198601093140202

Heinonen, S., Jartti, T., Garcia, C., Oliva, S., Smitherman, C., Anguiano, E., et al. (2016). Value of host transcriptome analysis. Rhinovirus detect. Symptomatic asymptomatic child. Am. J. Respir. Crit. Care Med. 193, 772-782. doi: 10.1164/rccm.201504-0749OC

Hiatt, P. W., Grace, S. C., Kozinetz, C. A., Raboudi, S. H., Treece, D. G., Taber, L. H., et al. (1999). Effects of viral lower respiratory tract infection on lung function in infants with cystic fibrosis. Pediatrics 103, 619-626. doi: 10.1542/peds.103.3.619
Hisert, K. B., Heltshe, S. L., Pope, C., Jorth, P., Wu, X., Edwards, R. M., et al. (2017). Restoring cystic fibrosis transmembrane conductance regulator function reduces airway bacteria and inflammation in people with cystic fibrosis and chronic lung infections. Am. J. Respir. Crit. Care Med. 195, 1617-1628. doi: 10.1164/rccm.201609-1954OC

Jacobs, S. E., Lamson, D. M., St George, K., and Walsh, T. J. (2013). Human rhinoviruses. Clin. Microbiol. Rev. 26, 135-162. doi: 10.1128/CMR.00077-12

Jayaraman, A., Jackson, D. J., Message, S. D., Pearson, R. M., Aniscenko, J., Caramori, G., et al. (2014). IL-15 complexes induce NK- and T-cell responses independent of type i IFN signaling during rhinovirus infection. Mucosal Immunol. 7, 1151-1164. doi: 10.1038/mi.2014.2

Jin, B., Wang, W., Du, G., Huang, G. Z., Han, L. T., Tang, Z. Y., et al. (2015). Identifying hub genes and dysregulated pathways in hepatocellular carcinoma. Eur. Rev. Med. Pharmacol. Sci. 19, 592-601.

Kieninger, E., Singer, F., Tapparel, C., Alves, M. P., Latzin, P., Tan, H. L., et al. (2013). High rhinovirus burden in lower airways of children with cystic fibrosis. Chest 143, 782-790. doi: 10.1378/chest.12-0954

Lai, H.-C., FitzSimmons, S. C., Allen, D. B., Kosorok, M. R., Rosenstein, B. J., Campbell, P. W., et al. (2000). Risk of persistent growth impairment after alternate-day prednisone treatment in children with cystic fibrosis. N. Engl. J. Med. 342, 851-859. doi: 10.1056/NEJM200003233421204

Lee, H., Kang, S., and Kim, W. (2016). Drug repositioning for cancer therapy based on large-scale drug-induced transcriptional signatures. PLoS ONE 11:e0150460. doi: 10.1371/journal.pone.0150460

Leigh, R., Oyelusi, W., Wiehler, S., Koetzler, R., Zaheer, R. S., Newton, R., et al. (2008). Human rhinovirus infection enhances airway epithelial cell production of growth factors involved in airway remodeling. J. Allergy Clin. Immunol. 121, 1238.e4-1245.e4. doi: 10.1016/j.jaci.2008.01.067

Lewis-Rogers, N., Seger, J., and Adler, F. R. (2017). Human rhinovirus diversity and evolution: how strange the change from major to minor. J. Virol. 91, e01659-e01616. doi: 10.1128/JVI.01659-16

Looi, K., Buckley, A. G., Rigby, P. J., Garratt, L. W., Iosifidis, T., Zosky, G. R., et al. (2018). Effects of human rhinovirus on epithelial barrier integrity and function in children with asthma. Clin. Exp. Allergy 48, 513-524. doi: 10.1111/cea.13097

Ma, J., Rubin, B. K., and Voynow, J. A. (2018). Mucins, mucus, and goblet cells. Chest 154, 169-176. doi: 10.1016/j.chest.2017.11.008

McKinlay, M. A., Pevear, D. C., York, N., and Rossmann, M. G. (1992). Treatment of the picornavirus common cold by inhibitors or viral uncoating and attachment. Annu. Rev. Microbiol. 46, 635-654. doi: 10.1146/annurev.mi.46.100192.003223

Monto, A. S., Shope, T. C., Schwartz, S. A., and Albrecht, J. K. (1986). Intranasal interferon-alpha $2 \mathrm{~b}$ for seasonal prophylaxis of respiratory infection. J. Infect. Dis. 154, 128-133. doi: 10.1093/infdis/154.1.128

Mortazavi, A., Williams, B. A., McCue, K., Schaeffer, L., and Wold, B. (2008). Mapping and quantifying mammalian transcriptomes by RNA-Seq. Nat. Methods 5, 621-628. doi: 10.1038/nmeth.1226

Mott, L. S., Park, J., Murray, C. P., Gangell, C. L., De Klerk, N. H., Robinson, P. J., et al. (2012). Progression of early structural lung disease in young children with cystic fibrosis assessed using CT. Thorax 67, 509-516. doi: 10.1136/thoraxjnl-2011-200912

Mousnier, A., Bell, A. S., Swieboda, D. P., Morales-Sanfrutos, J., Pérez-Dorado, I., Brannigan, J. A., et al. (2018). Fragment-derived inhibitors of human Nmyristoyltransferase block capsid assembly and replication of the common cold virus. Nat. Chem. 10, 599-606. doi: 10.1038/s41557-018-0039-2

Olesen, H. V., Nielsen, L. P., and Schiotz, P. O. (2006). Viral and atypical bacterial infections in the outpatient pediatric cystic fibrosis clinic. Pediatr. Pulmonol. 41, 1197-1204. doi: 10.1002/ppul.20517

Painter, R. G., Bonvillain, R. W., Valentine, V. G., Lombard, G. A., LaPlace, S. G. Nauseef, W. M., et al. (2008). The role of chloride anion and CFTR in killing of Pseudomonas aeruginosa by normal and CF neutrophils. J. Leukoc. Biol. 83, 1345-1353. doi: 10.1189/jlb.0907658

Palmenberg, A. C. (2017). Rhinovirus C, asthma, and cell surface expression of virus receptor CDHR3. J. Virol. 91:e00072-17. doi: 10.1128/JVI.00072-17

Palmenberg, A. C., and Gern, J. E. (2015). Classification and evolution of human rhinoviruses. Methods Mol. Biol. 1221, 1-10. doi: 10.1007/978-1-4939-1571-2_1

Pribble, C. G., Black, P. G., Bosso, J. A., and Turner, R. B. (1990). Clinical manifestations of exacerbations of cystic fibrosis associated with nonbacterial infections. J. Pediatr. 117, 200-204. doi: 10.1016/S0022-3476(05)80530-X 
Proud, D., Sanders, S. P., and Wiehler, S. (2004). Human rhinovirus infection induces airway epithelial cell production of human beta-defensin 2 both in vitro and in vivo. J. Immunol. 172, 4637-4645. doi: 10.4049/jimmunol.172.7.4637

Rosen, B. H., Chanson, M., Gawenis, L. R., Liu, J., Sofoluwe, A., Zoso, A., et al. (2018). Animal and model systems for studying cystic fibrosis. J. Cyst. Fibros. 17, S28-S34. doi: 10.1016/j.jcf.2017.09.001

Ruuskanen, O., Waris, M., and Kainulainen, L. (2014). Treatment of persistent rhinovirus infection with pegylated interferon $\alpha 2 \mathrm{a}$ and ribavirin in patients with hypogammaglobulinemia. Clin. Infect. Dis. 58, 1784-1786. doi: $10.1093 / \mathrm{cid} / \mathrm{ciu} 169$

Safari-Alighiarloo, N., Taghizadeh, M., Tabatabaei, S. M., Shahsavari, S., Namaki, S., Khodakarim, S., et al. (2016). Identification of new key genes for type 1 diabetes through construction and analysis of the protein-protein interaction networks based on blood and pancreatic islet transcriptomes. J. Diabetes 9, 764-777. doi: 10.1111/1753-0407.12483

Sanders, S. P., Siekierski, E. S., Porter, J. D., Richards, S. M., and Proud, D. (1998). Nitric oxide inhibits rhinovirus-induced cytokine production and viral replication in a human respiratory epithelial cell line. J. Virol. 72, 934-942.

Schögler, A., Kopf, B. S., Edwards, M. R., Johnston, S. L., Casaulta, C., Kieninger, E., et al. (2014). Novel antiviral properties of azithromycin in cystic fibrosis airway epithelial cells. Eur. Respir. J. 45, 428-439. doi: 10.1183/09031936.00102014

Sessions, O. M., Tan, Y., Goh, K. C., Liu, Y., Tan, P., Rozen, S., et al. (2013). Host cell transcriptome profile during wild-type and attenuated dengue virus infection. PLoS Negl. Trop. Dis. 7:e2107. doi: 10.1371/journal.pntd.0002107

Shah, A., Connelly, M., Whitaker, P., McIntyre, C., Etherington, C., Denton, M., et al. (2015). Pathogenicity of individual rhinovirus species during exacerbations of cystic fibrosis. Eur. Respir. J. 45, 1748-1751. doi: 10.1183/09031936.00229114

Sirota, M., Dudley, J. T., Kim, J., Chiang, A. P., Morgan, A. A., Sweet-Cordero, A., et al. (2011). Discovery and preclinical validation of drug indications using compendia of public gene expression data. Sci. Transl. Med. 3:96ra77. doi: 10.1126/scitranslmed.3003215

Sly, P. D., Gangell, C. L., Chen, L., Ware, R. S., Ranganathan, S., Mott, L. S., et al. (2013). Risk factors for bronchiectasis in children with cystic fibrosis. N. Engl. J. Med. 368, 1963-1970. doi: 10.1056/NEJMoa1301725

Smyth, A. R., Smyth, R. L., Tong, C. Y., Hart, C. A., and Heaf, D. P. (1995). Effect of respiratory virus infections including rhinovirus on clinical status in cystic fibrosis. Arch. Dis. Child. 73, 117-120.

Sperber, S. J., Levine, P. A., Innes, D. J., Mills, S. E., and Hayden, F. G. (1988). Tolerance and efficacy of intranasal administration of recombinant $\beta$ (serine) interferon in healthy adults. J. Infect. Dis. 158, 166-175. doi: 10.1093/infdis/158.1.166

Stein, R. A. (2017). Hopes and challenges for the common cold. Int. J. Clin. Pract. 71:e12921. doi: 10.1111/ijcp.12921

Stelzer-Braid, S., Johal, H., Skilbeck, K., Steller, A., Alsubie, H., Tovey, E., et al. (2012). Detection of viral and bacterial respiratory pathogens in patients with cystic fibrosis. J. Virol. Methods 186, 109-112. doi: 10.1016/j.jviromet.2012.08.008

Stelzer-Braid, S., Liu, N., Doumit, M., D'Cunha, R., Belessis, Y., Jaffe, A., et al. (2017). Association of rhinovirus with exacerbations in young children affected by cystic fibrosis: preliminary data. J. Med. Virol. 89, 1494-1497. doi: 10.1002/jmv.24794

Sutanto, E. N., Kicic, A., Foo, C. J., Stevens, P. T., Mullane, D., Knight, D. A., et al. (2011). Innate inflammatory responses of pediatric cystic fibrosis airway epithelial cells: effects of nonviral and viral stimulation. Am. J. Respir. Cell Mol. Biol. 44, 761-767. doi: 10.1165/rcmb.2010$0368 \mathrm{OC}$

Tacon, C. E., Wiehler, S., Holden, N. S., Newton, R., Proud, D., and Leigh, R. (2010). Human rhinovirus infection up-regulates MMP-9 production in airway epithelial cells via NF-\{kappa\}B. Am. J. Respir. Cell Mol. Biol. 43, 201-209. doi: $10.1165 / \mathrm{rcmb} .2009-0216 \mathrm{OC}$

Turner, R. B., Wecker, M. T., Pohl, G., Witek, T. J., McNally, E., St George, R., et al. (1999). Efficacy of tremacamra, a soluble intercellular adhesion molecule 1, for experimental rhinovirus infection: a randomized clinical trial. JAMA 281, 1797-1804.

Unger, B. L., Ganesan, S., Comstock, A. T., Faris, A. N., Hershenson, M. B., and Sajjan, U. S. (2014). Nod-Like Receptor X-1 Is Required for RhinovirusInduced Barrier Dysfunction in Airway Epithelial Cells. J. Virol. 88, 3705-3718. doi: 10.1128/JVI.03039-13

van Ewijk, B. E., van der Zalm, M. M., Wolfs, T. F. W., and van der Ent, C. K. (2005). Viral respiratory infections in cystic fibrosis. J. Cyst. Fibros. 4(Suppl. 2), 31-36. doi: 10.1016/j.jcf.2005.05.011

Vareille, M., Kieninger, E., Edwards, M. R., and Regamey, N. (2011). The airway epithelium: soldier in the fight against respiratory viruses. Clin. Microbiol. Rev. 24, 210-229. doi: 10.1128/CMR.00014-10

Vlaic, S., Conrad, T., Tokarski-Schnelle, C., Gustafsson, M., Dahmen, U., Guthke, R., et al. (2018). ModuleDiscoverer: identification of regulatory modules in protein-protein interaction networks. Sci. Rep. 8:433. doi: 10.1038/s41598-017-18370-2

Wagener, A. H., Zwinderman, A. H., Luiten, S., Fokkens, W. J., Bel, E. H., Sterk, P. J., et al. (2014). dsRNA-induced changes in gene expression profiles of primary nasal and bronchial epithelial cells from patients with asthma, rhinitis and controls. 15:9. doi: 10.1186/1465-9921-15-9

Wark, P. A. B., Tooze, M., Cheese, L., Whitehead, B., Gibson, P. G., Wark, K. F., et al. (2012). Viral infections trigger exacerbations of cystic fibrosis in adults and children. Eur. Respir. J. 40, 510-512. doi: 10.1183/09031936.00202311

Wat, D. (ed.). (2015). "Respiratory virus in cystic fibrosis - a review of the literature," in Cystic Fibrosis in the Light of New Research (InTechOpen), 143-169. doi: 10.5772/60905

Wat, D., Gelder, C., Hibbitts, S., Cafferty, F., Bowler, I., Pierrepoint, M., et al. (2008). The role of respiratory viruses in cystic fibrosis. J. Cyst. Fibros. 7, 320-328. doi: 10.1016/j.jcf.2007.12.002

Waters, V., and Ratjen, F. (2015). Pulmonary exacerbations in children with cystic fibrosis. Ann. Am. Thorac Soc. 12 (Suppl 2), S200-S206. doi: 10.1513/AnnalsATS.201502-098AW

Whitsett, J. A., and Alenghat, T. (2015). Respiratory epithelial cells orchestrate pulmonary innate immunity. Nat. Immunol. 16, 27-35. doi: 10.1038/ni.3045

Worrall, G. (2011). Common cold. Can. Fam. Physician 57, 1289-1290.

Yeo, N.-K., and Jang, Y. J. (2010). Rhinovirus infection-induced alteration of tight junction and adherens junction components in human nasal epithelial cells. Laryngoscope 120, 346-352. doi: 10.1002/lary.20764

Zaman, N., Li, L., Jaramillo, M. L., Sun, Z., Tibiche, C., Banville, M., et al. (2013). Signaling network assessment of mutations and copy number variations predict breast cancer subtype-specific drug targets. Cell Rep. 5, 216-223. doi: 10.1016/j.celrep.2013.08.028

Conflict of Interest Statement: The authors declare that the research was conducted in the absence of any commercial or financial relationships that could be construed as a potential conflict of interest.

Copyright (C) 2018 Ling, Garratt, Lassmann, Stick, Kicic, WAERP, AusREC and Australian Respiratory Early Surveillance Team for Cystic Fibrosis. This is an openaccess article distributed under the terms of the Creative Commons Attribution License (CC BY). The use, distribution or reproduction in other forums is permitted, provided the original author(s) and the copyright owner(s) are credited and that the original publication in this journal is cited, in accordance with accepted academic practice. No use, distribution or reproduction is permitted which does not comply with these terms. 